\title{
Milk-borne lactocrine-acting factors affect gene expression patterns in the developing neonatal porcine uterus
}

\author{
Joseph C Chen, Amy-Lynn Frankshun, Anne A Wiley ${ }^{1}$, Dori J Miller ${ }^{1}$, Kristene A Welch, \\ Teh-Yuan Ho, Frank F Bartol ${ }^{1}$ and Carol A Bagnell \\ Department of Animal Sciences, Rutgers University, 84 Lipman Drive, New Brunswick, New Jersey 08901, USA and \\ ${ }^{1}$ Department of Anatomy, Physiology and Pharmacology, Cellular and Molecular Biosciences Program, Auburn \\ University, Auburn, Alabama 36849, USA
}

Correspondence should be addressed to C A Bagnell; Email: bagnell@aesop.rutgers.edu

C A Bagnell and F F Bartol contributed equally to this work

\begin{abstract}
Lactocrine communication of milk-borne bioactive factors $(\mathrm{MbFs})$ from mother to offspring through nursing can affect neonatal development with lasting consequences. Relaxin (RLX), a lactocrine-active peptide found in porcine colostrum, stimulates estrogen receptor- $\alpha$ (ESR1) expression required for uterine development shortly after birth (postnatal day=PND 0). Whether other MbFs or cooperative lactocrine mechanisms affect the neonatal uterine developmental program is unknown. To determine the effects of age, nursing, and exogenous RLX on gene expression associated with uterine development, gilts ( $n=4-5 /$ group) were assigned to nurse ad libitum or to receive milk replacer, with or without exogenous RLX (20 $\mu \mathrm{g} / \mathrm{kg} \mathrm{BW} \mathrm{i.m./6} \mathrm{h} \mathrm{for} 48 \mathrm{~h}$ ), from birth to PND $2 \mathrm{when}$ uteri were collected. Body weight and uterine weight increased $(P<0.05)$ similarly from birth to PND 2 in all gilts. However, colostrum consumption was required for normal uterine ESR1, vascular endothelial growth factor (VEGFA), matrix metalloproteinase 9 (MMP9), and RLX receptor (RXFP1) protein and/or transcript expression on PND 2. Uterine ESR1, VEGFA, and MMP9 protein levels were below $(P<0.01)$ the assay sensitivity in replacer-fed gilts. Supplemental $R L X$ increased $(P<0.05)$ uterine ESR1 protein and $m R N A$ in nursed gilts, as well as VEGFA protein in nursed and VEGFA mRNA in both nursed and replacer-fed gilts. RLX treatment did not affect uterine MMP9 mRNA levels. When compared with replacer-fed gilts on PND 2, uterine $R X F P 1$ mRNA was reduced $(P<0.05)$ in nursed gilts and in RLX-supplemented replacer-fed gilts. These results constitute the first evidence that establishment of the neonatal porcine uterine developmental program requires maternal lactocrine support.
\end{abstract}

Reproduction (2011) 141 675-683

\section{Introduction}

Birth marks the end of intrauterine life but does not mark the end of maternal influence over events that can define the neonatal developmental program (Bartol et al. 2008). Evidence in several species indicates that colostrum, the first milk secreted after birth in mammals, acts as a conduit for transmission of signaling molecules from mother to offspring (Ogra et al. 1977, Simmen et al. 1990, Grosvenor et al. 1993, Playford et al. 2000, Almeida et al. 2008, Langer 2009). Defined as lactocrine signaling (Yan et al. 2006b, Bartol et al. 2008), neonatal consumption of bioactive factors in colostrum affects differentiation of anterior pituitary mammotropes (Nusser \& Frawley 1997), gastrointestinal tract development (Shulman 1990, Donovan \& Odle 1994, Burrin et al. 1995), and immune system maturation (Lonnerdal 2003, Field 2005, Kosaka et al. 2010). Whether lactocrine-active factors or lactocrine signaling contributes to establishment of the neonatal developmental program for female reproductive tract tissues is unknown.

Development of the neonatal porcine uterine wall is marked by age-dependent expression of estrogen receptor- $\alpha$ (ESR1), which is low to undetectable at birth (postnatal day=PND 0; Yan et al. 2006a), evident in nascent endometrial glandular epithelium and underlying stroma by PND 2 (Yan et al. 2008), and develops in an endometrial cell compartment-specific manner during the first 2 weeks of postnatal life (Tarleton et al. 1999). Between birth and PND 3, the porcine endometrium undergoes an important morphogenetic transition, as glandular epithelium differentiates from luminal epithelium and nascent uterine glands begin to penetrate underlying stroma (Masters et al. 2007). These events are both ER dependent and estrogen sensitive (Bartol et al. 1993, Tarleton et al. 1999, 2003, Chen et al. 
2010). Data support the idea that factors affecting patterns of porcine uterine ESR1 expression and ER activation during early postnatal life define both the developmental program and trajectory of developing uterine tissues with lasting consequences in adults.

Relaxin (RLX), a prototypical milk-borne bioactive factor (MbF; Bartol et al. 2008, Frankshun et al. 2009), increases porcine uterine growth (Sherwood 2004, Yan et al. 2006a) and stimulates uterine matrix metalloproteinase 2 (MMP2) and MMP9 production and activity important for connective tissue remodeling (Lenhart et al. 2001). Administered from birth, exogenous RLX increased uterine weight and both ESR1 and vascular endothelial growth factor (VEGFA) expression in neonatal gilts (Yan et al. 2008). Based on observations for RLX, a prototypical MbF in the pig, the lactocrine hypothesis was proposed to explain how bioactive factors present in colostrum could be delivered into the neonatal circulation as a consequence of nursing and influence developing neonatal tissues (Yan et al. 2006b, Bartol et al. 2008). If the lactocrine hypothesis is valid, neonates consuming colostrum should display a different pattern of uterine gene expression than those fed a synthetic milk replacer devoid of MbFs.

Whether lactocrine signaling is required to i) establish the neonatal uterine developmental program; ii) determine uterine developmental trajectory; and iii) set the stage for uterine developmental success as reflected by functional uterine capacity to support pregnancy remains to be determined. To address the first of these issues, the objectives of this study were to determine the effects of age and consumption of colostrum, in the presence and absence of exogenous RLX for 2 days from birth, on the expression of molecular markers and mediators of neonatal porcine uterine development at PND 2. Results of this study provide the first direct test of the lactocrine hypothesis for maternal regulation of neonatal uterine development.

\section{Results}

\section{Neonatal body weight and uterine weight in newborn and PND 2 animals}

Data for body weight and uterine wet weight are presented in Fig. 1. Newborn gilt body weight (Fig. 1A) averaged $1.4 \mathrm{~kg}$ and increased $(P<0.05)$ by PND 2 $(2.1 \pm 0.01 \mathrm{~kg})$ to a similar extent in both nursing and replacer-fed animals (Fig. 1A). At PND 2, there were no differences in body weight among any of the treatment groups. Uterine wet weight for gilts at birth (Fig. 1B) averaged $0.22 \mathrm{~g}$ and increased $(P<0.05)$ by PND 2 $(0.3 \pm 0.01 \mathrm{~g})$ to a similar extent for both nursing and replacer-fed animals. Administration of RLX from birth in nursing gilts further increased $(P<0.05)$ uterine weight compared with all other PND 2 groups (Fig. 1B).
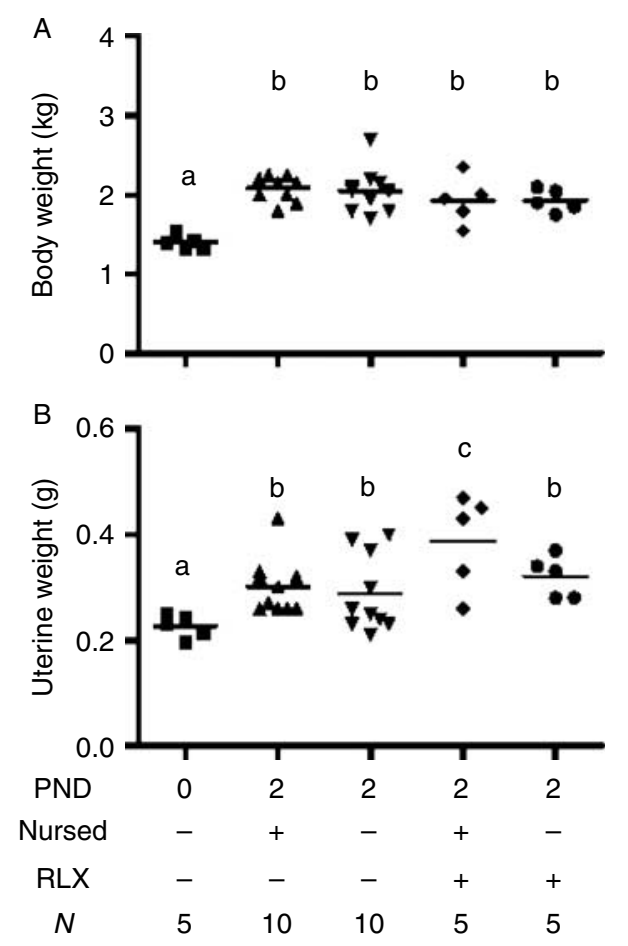

Figure 1 Effects of age, nursing, and RLX on neonatal porcine body weight (A) and uterine weight (B). Individual weight is presented, and horizontal bars indicate LSM. $N$, animals per group. Different letters indicate differences at $P<0.05$.

\section{Neonatal uterine ESR1 and VEGFA protein levels in nursed and replacer-fed gilts}

Neonatal gilts that nursed during the first $48 \mathrm{~h}$ of life expressed a single $51 \mathrm{kDa}$ uterine protein band, corresponding to ESR1 (Fig. 2A), and a $46 \mathrm{kDa}$ band, corresponding to dimeric VEGFA protein (Fig. 2B) at PND 2. Surprisingly, neither uterine ESR1 nor VEGF protein was detectable $(P<0.01)$ in gilts that ingested milk replacer in lieu of nursing for 2 days from birth (Fig. 2A and B). Similar results (data not shown) were obtained using a different ESR1-specific primary antibody (DAKO mouse anti-human ESR1; Carpinteria, CA, USA; Nishihara et al. 2000).

\section{Effects of age, nursing, and RLX on neonatal uterine ESR1 and VEGFA protein}

At birth, prior to nursing, uterine ESR1 and VEGFA protein bands were undetectable. However, by PND 2, uterine ESR1 and VEGFA, consistently and clearly detectable in animals that nursed from birth, were undetectable in uteri of replacer-fed animals (Fig. 3A). RLX administration increased $(P<0.05)$ uterine expression of both ESR1 and VEGFA protein in nursing animals (Fig. 3B and C), whereas similar treatment with RLX failed to induce the expression of either of these uterine proteins in gilts fed milk replacer from birth. 

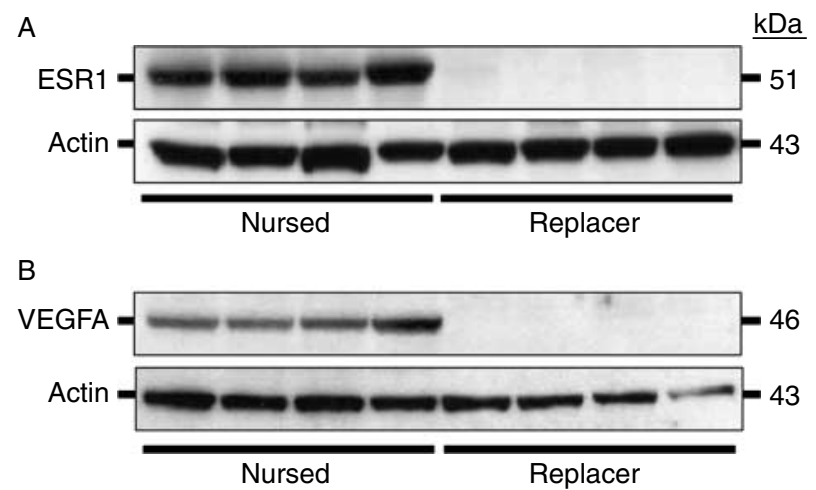

Figure 2 Effects of nursing versus milk replacer ingestion on porcine uterine ESR1 (A) and VEGFA (B) proteins at PND 2. Representative immunoblots are shown. Both 51 and $46 \mathrm{kDa}$ immunoreactive bands for ESR1 and VEGFA respectively are indicated. An immunoreactive band for actin was detected at $43 \mathrm{kDa}$ and included as a loading reference. $N=5-10$ animals per group.

\section{Effects of age, nursing, and RLX on neonatal uterine MMP9 and MMP2 protein}

Immunoblot analyses were used to identify the type and measure the relative abundance of MMP2 and MMP9 protein in neonatal uterine tissues (Fig. 4). At PND 0, prior to nursing, uterine MMP9 was undetectable. However, by PND 2, protein bands at 92 and $84 \mathrm{kDa}$, the reported sizes of proMMP9 and active MMP9 respectively $\left(\mathrm{O}^{\prime}\right.$ Connell et al. 1994) were induced in uteri of gilts nursed from birth (Fig. 4A) but remained undetectable in replacer-fed gilts. Exogenous RLX administration did not affect the expression of uterine MMP9 protein at PND 2 in nursed or replacer-fed gilts (Fig. 4B). A $72 \mathrm{kDa}$ protein band corresponding to proMMP2 and, to a lesser extent, a $66 \mathrm{kDa}$ band corresponding to active MMP2 (Crabbe et al. 1993) were detected in uteri from all groups (Fig. 4A). Neither age, nursing nor RLX treatment affected the relative expression of uterine proMMP2 or MMP2 (Fig. 4A and C).

\section{Effects of age, nursing, and RLX on neonatal uterine gene expression}

As illustrated in Fig. 5A, uterine expression of ESR1 mRNA was detected at PND 0 and, to a greater extent, in nursing but not in replacer-fed gilts at PND 2. RLX treatment of nursing animals further increased uterine ESR1 transcripts compared with nursing alone, whereas exposure to RLX had no effect on uterine ESR1 mRNA in replacer-fed animals. Uterine VEGFA mRNA expression was low in PND 0, nursing, and replacer-fed groups but increased $(P<0.05)$ in response to exogenous RLX from birth in both nursed and replacer-fed gilts (Fig. 5B). Neither age, nursing nor RLX treatment affected the relative expression of uterine MMP9 (Fig. 5C) or MMP2 gene expression (data not shown). Detectable at birth,
RXFP1 mRNA expression remained at PND 0 levels in replacer-fed gilts on PND 2 but was reduced $(P<0.05)$ at PND 2 in gilts that nursed from birth and in response to exogenous RLX in both the groups (Fig. 5D).

\section{Discussion}

This study provides the first test of the lactocrine hypothesis for maternal regulation of postnatal uterine development. Results of this study show that maternal lactocrine signaling is necessary to support normal patterns of gene expression associated with the establishment of the neonatal porcine uterine developmental program within the first 2 days of postnatal life. Evidence presented in this study in support of the lactocrine hypothesis constitutes a critical first step in efforts aimed at defining the extent to which lactocrine signaling is required to determine both the uterine developmental trajectory and functional uterine capacity in adults. Evidence indicating that uterine expression of ESR1, VEGFA, MMP9, and RXFP1 can be modulated predictably by RLX in nursing but not in replacer-fed animals suggests that cooperating lactocrine-active
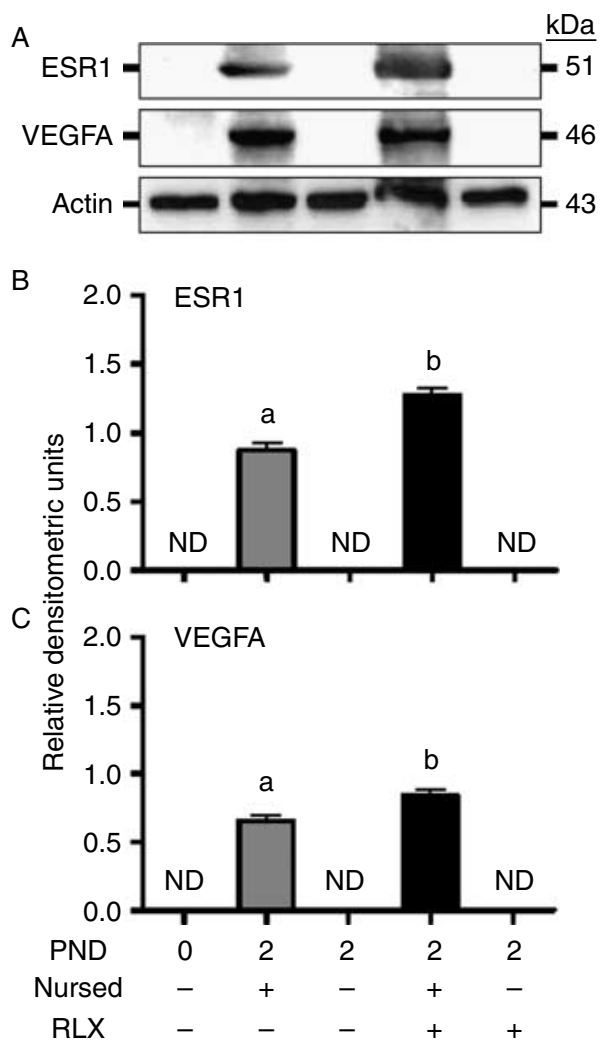

Figure 3 Effects of age, nursing, and RLX on neonatal porcine uterine ESR1 and VEGFA protein levels. Representative immunoblots (A) are shown. Densitometric data for the relative expression of ESR1 (B) and VEGFA (C) are presented as LSM \pm s.E.M. $N=4-5$ animals per group. Signals below the detection range are marked non-detectable (ND). Different letters indicate differences at $P<0.05$. 


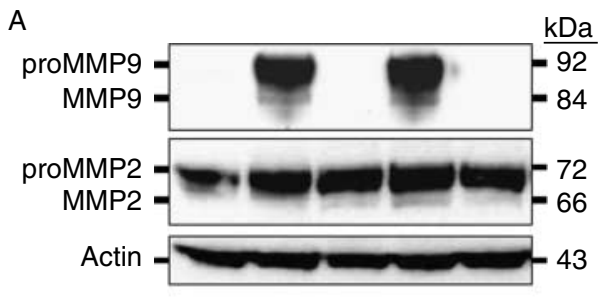

B

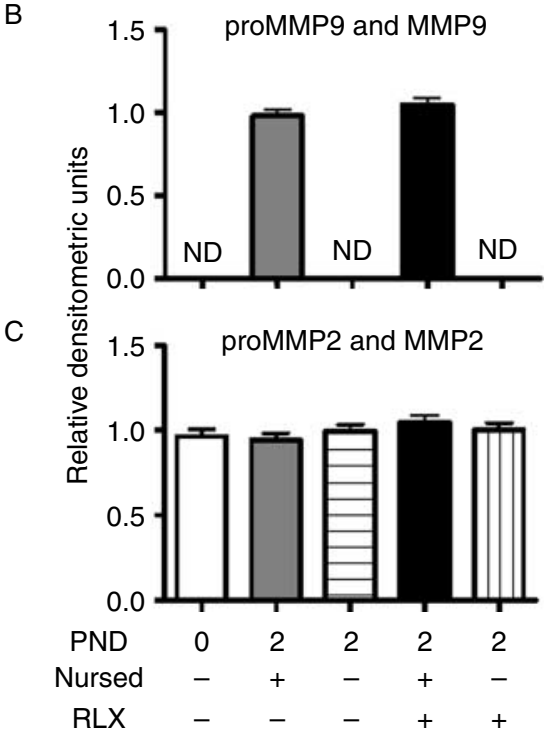

Figure 4 Effects of age, nursing, and RLX on neonatal porcine uterine MMP9 and MMP2 protein. Representative immunoblots (A) are shown. Immunoreactive bands for proMMP9 (92 kDa) and MMP9 (86 kDa), as well as for proMMP2 $(72 \mathrm{kDa})$ and MMP2 $(66 \mathrm{kDa})$ are indicated. An immunoreactive band for actin was detected at $43 \mathrm{kDa}$ and included as a loading reference. Densitometric data for the relative expression of MMP9 (B) and MMP2 (C), including respective proforms, are presented as $L S M \pm$ S.E.M. $N=4-5$ animals per group. Signals below the detection range are marked as non-detectable (ND).

factors may be required to support the actions of specific MbFs, including RLX.

Similarities in both body weight and uterine weight observed for nursed and replacer-fed gilts on PND 2 (Fig. 1) indicate that replacer-feeding did not compromise the growth of neonatal gilts. Thus, treatment-related uterine responses reported in this study were not biased by differences in either body weight or organ weight. Consistent with previous reports (Yan et al. 2006a, 2008), exogenous RLX increased uterine weight on PND 2 in nursing gilts. The fact that uterotrophic effects of exogenous RLX were more pronounced in nursing gilts than in replacer-fed gilts (Fig. 1) supports a role for cooperative, lactocrine-acting factors in such responses.

In this study, no attempt was made to evaluate the effects of orally administered RLX in the presence and absence of lactocrine signaling. This decision was based upon the observation that the $18 \mathrm{kDa}$ proRLX molecule, not the $6 \mathrm{kDa}$ native RLX molecule, is the primary form of bioactive RLX present in porcine colostrum/milk
(Frankshun et al. 2009). The extent to which neonatal consumption of the proRLX molecule, within which the native $6 \mathrm{kDa}$ RLX molecule is encrypted, may be important to facilitate lactocrine delivery and transport of this peptide hormone has yet to be determined.

Neonatal porcine uterine development is both ESR1 dependent and estrogen sensitive (Bartol et al. 1993, Tarleton et al. 1999, 2003, Chen et al. 2010). Therefore, it was important to determine the extent to which uterine ESR1 expression might be regulated via a lactocrine mechanism. The present results show that the increase in
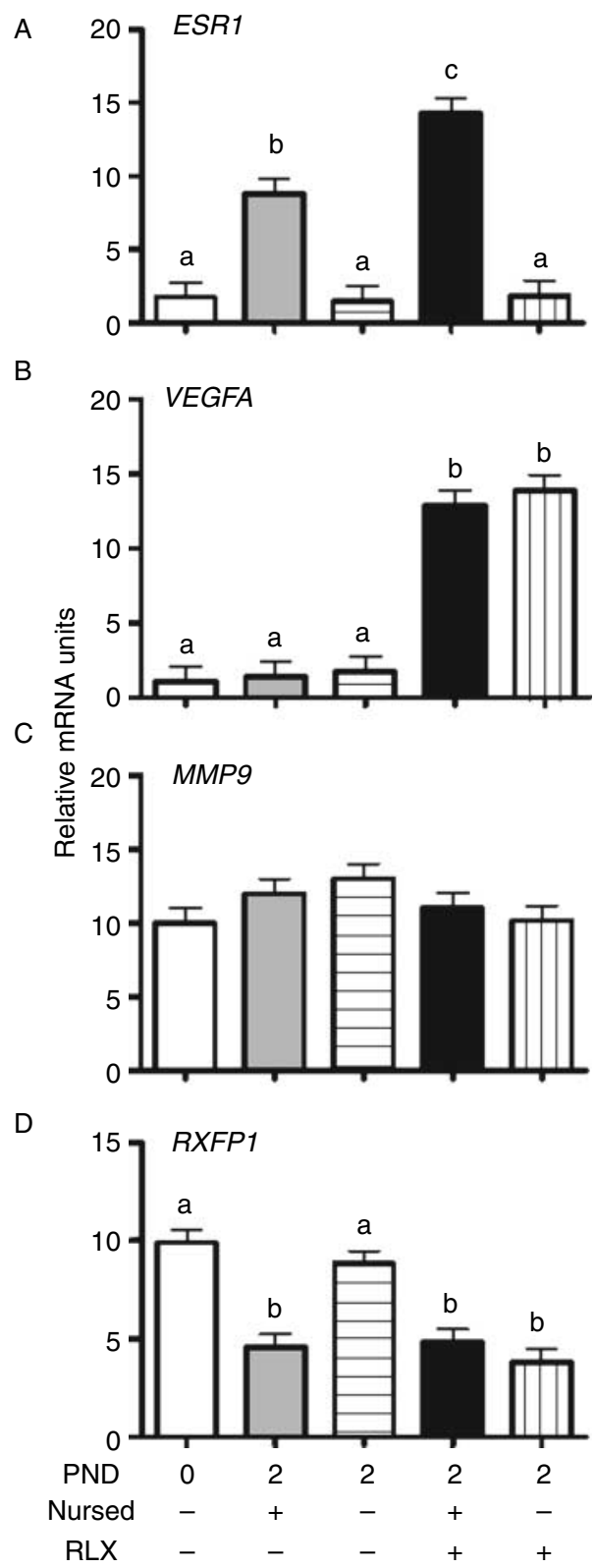

Figure 5 Effects of age, nursing, and RLX on neonatal porcine uterine expression of ESR1 (A), VEGFA (B), MMP9 (C), and RXFP1 (D) transcripts were determined by qPCR. Data were normalized to $18 S$ gene expression and are presented as LSM \pm S.E.M. $N=4-5$ animals per group. Letters a and b indicate $P<0.05$; c indicates $P=0.09$. 
uterine ESR1 expression expected by PND 2 (Yan et al. 2008) occurred only in those gilts allowed to consume colostrum from birth. These results support the idea that lactocrine regulation of neonatal uterine ESR1 expression involves complementary actions at transcriptional and translational levels. Interestingly, the prototypical MbF estradiol (Osterlundh et al. 1998) can increase ESR1 mRNA stability and decrease transcript degradation (Ing \& Ott 1999). Such actions could contribute to conditions associated with reduced uterine ESR 1 mRNA levels observed in replacer-fed gilts compared with nursing gilts on PND 2. Consistent with the present results for uterine wet weight (Fig. 1), exogenous RLX did not affect uterine ESR1 mRNA or protein levels in replacer-fed gilts. These results suggest a mechanism involving lactocrine-acting factors cooperating in support of normal, RLX-sensitive uterine growth and ESR1 expression dynamics.

A marker of both RLX (Unemori et al. 1999) and estrogen (Cullinan-Bove \& Koos 1993) action, VEGFA supports angiogenesis and related events associated with the growth of many tissues (Neufeld et al. 1999, Cebe-Suarez et al. 2006), including rodent and porcine endometria (Welter et al. 2003). Data for neonatal uterine VEGFA expression reported in this study, particularly at the protein level, were complementary to those observed for ESR1. The dramatic reduction in VEGFA protein expression observed for replacer-fed gilts compared with nursing gilts on PND 2 (Figs 1 and 2), considered in light of the absence of a similar effect for VEGFA mRNA levels (Fig. 5B), suggests that lactocrine regulation of uterine VEGFA expression occurs primarily at the translational level. Consistently, RLX administration increased uterine VEGFA mRNA levels to a similar extent in both nursed and replacer-fed gilts on PND 2 but increased uterine VEGFA protein levels only in nursed gilts. The latter observation agrees with results reported previously for nursing gilts (Yan et al. 2008). Present results support the idea that a cooperative lactocrine mechanism is required to support translational events necessary to achieve a normal uterine expression level for this peptide growth factor. Relationships reported in this study may also be explained, in part, by evidence showing that secretion of VEGFA protein by human endometrial stromal cells was dependent on ESR1 expression (Huang et al. 1998). In this study, uterine ESR1 expression was suppressed and, therefore, VEGFA protein expression was reduced in replacer-fed animals.

Gelatinases MMP2 and MMP9 digest type IV and V collagens in basement membranes to facilitate tissue growth and remodeling (Zeng et al. 1999, O'Farrell \& Pourmotabbed 2000). Both MMP2 and MMP9 were detected in the murine uterus (Hu et al. 2004) and human endometrial cells (Martelli et al. 1993, Iwahashi et al. 1996). In the prepubertal porcine uterus, RLX increased the secretion of both MMP2 and MMP9 (Lenhart et al. 2001). Given that RLX is a component of porcine colostrum/milk (Yan et al. 2006b, Frankshun et al. 2009), it was hypothesized that the uterine expression of these enzymes could be sensitive to lactocrine regulation.

Consistent with this hypothesis, neonatal uterine expression of MMP9, but not of MMP2, was clearly lactocrine dependent at the protein level. As observed for ESR1 and VEGFA, normal expression of MMP9 protein required lactocrine support, as uterine MMP9 protein levels were below assay sensitivity in replacerfed gilts. However, in contrast to data for ESR1 and VEGFA, mRNA levels for MMP9 were unaffected by age, the absence of colostrum/replacer-feeding, and administration of exogenous RLX. Thus, as suggested for VEGFA, lactocrine regulation of neonatal uterine MMP9 expression may involve translational control. The absence of an effect of exogenous RLX on uterine expression of either MMP2 or MMP9 at PND 2 suggests that RLX sensitivity associated with regulated expression of these proteins develops later in life. Patterns of MMP2 expression observed in this study support the idea that some neonatal uterine gene expression events are not sensitive to lactocrine regulation between birth and PND 2.

Results for VEGFA and MMP9 illustrate some discordance between uterine transcriptional and translational events. While mechanisms were unclear, dissimilarities between mRNA measurements and both protein expression and activity patterns were described by others for both VEGFA and MMP9 (Kuo et al. 1999, Zhang et al. 2007). Discordance between transcriptional and translational events does occur, and evidence for gene-specific translational control is well documented (Pavitt 2005, Sonenberg \& Hinnebusch 2009). Translational control of gene expression can be particularly important during development and differentiation of eukaryotic cells and tissues (Sonenberg \& Hinnebusch 2009). As is the case for other transcripts, translation of both VEGFA (De Benedetti \& Graff 2004, Zhou et al. 2006) and MMP9 (Graff et al. 1995, De Benedetti \& Graff 2004) involves eukaryotic initiation factor elF-4E, a critical component of cap-dependent translation (Sonenberg \& Hinnebusch 2009). Expression of both of these lactocrine-sensitive factors may be regulated translationally to a significant degree.

Recently, RXFP1 was identified as the central element of a feed-forward, lactocrine-driven mechanism regulating establishment of the neonatal porcine uterine developmental program (Bartol et al. 2009). The present results corroborate this scheme, in which milk-borne RLX, acting via RXFP1 expressed in uterine tissues at birth (Yan et al. 2006b), supports or induces uterine expression of ESR1 and the parallel expression of VEGFA and other relaximedins and estromedins (Bartol et al. 2009). This, in turn, may insure continued uterine expression of both RXFP1 and ESR1, as well as propagation of related signaling events essential to the 
success of endometrial development. Lactocrine regulation of uterine RXFP1 expression was also clear. However, in contrast to the results presented for ESR1 mRNA (Fig. 5), uterine RXFP1 transcript levels were reduced in nursed gilts compared with replacer-fed gilts on PND 2. Interestingly, RLX administered to replacerfed gilts reduced uterine RXFP1 expression to levels similar to those observed for nursed gilts, but not different from those observed for nursed gilts supplemented with exogenous RLX (Fig. 5). These relationships suggest a RLX-specific effect that was not further modulated by cooperating lactocrine-active factors. These results are also consistent with the idea that RXFP1 expression can be regulated by its cognate ligand (Parry et al. 2005, Yan et al. 2008).

Evidence reviewed in this study supports the lactocrine hypothesis for maternal programming of porcine neonatal uterine development and reinforces the role of RLX as a lactocrine-acting MbF (Bagnell et al. 2009, Bartol et al. 2009). Of course, many other factors found in colostrum/milk are likely to be acting via a lactocrine mechanism to affect development of the uterus and other reproductive and somatic tissues. It is well known that steroid and peptide hormones, cytokines, and growth factors are present in colostrum/milk (Grosvenor et al. 1993, Osterlundh et al. 1998, Playford et al. 2000, Salmon et al. 2009). Recently, microRNAs, which can regulate gene expression by silencing translation (Alvarez-Garcia \& Miska 2005), were identified in human and bovine milk (Hata et al. 2010, Kosaka et al. 2010). Thus, microRNAs must also be added to the list of MbFs with the potential to affect neonatal development.

Likewise, bioactive peptides encrypted in colostral/ milk proteins (Hartmann et al. 2007) may also contribute to lactocrine signaling events. Evidence indicating that neonatal consumption of milk replacer can affect patterns of gastrointestinal tract maturation and function (Simmen et al. 1990, Zabielski et al. 2008, Chapkin et al. 2010) should also be considered, as such differences could affect the efficiency of lactocrine signaling processes, which are yet to be defined.

The present results indicate that initiation of the porcine uterine developmental program during the first 2 days of life is supported, in part, by lactocrine-acting $\mathrm{MbFs}$ delivered to the neonate as a consequence of nursing and the ingestion of colostrum. Such lactocrine effects may be necessary to establish a trajectory of uterine development that will define the mature uterine phenotype. The stage is now set for studies designed to evaluate the extent to which maternally driven, lactocrine-mediated signaling affects the development and function of reproductive and non-reproductive tissues in both males and females. Much remains to be learned about the nature of lactocrine-active factors and their role in regulating the development of mammalian neonates.

\section{Materials and Methods}

\section{Materials}

Advance Liqui-Wean, a nutritionally complete commercial piglet milk replacer, was purchased from MSC Speciality Nutrition (Carpentersville, IL, USA). Purified porcine RLX, provided by Dr O D Sherwood (University of Illinois, Urbana, IL, USA), was isolated from pregnant sow ovaries, and bioactivity was determined as described previously (Sherwood \& O'Byrne 1974). Beuthanasia-D Special was purchased from Intervet/Schering Plough Animal Health (Whitehouse Station, NJ, USA). TRI Reagent was obtained from Sigma-Aldrich, and RNeasy Mini kits, RNase-Free DNase Sets, and RNALater were from Qiagen, Inc. SuperScript III First-Strand Synthesis System for RT-PCR was from Invitrogen. SYBR Green PCR Master Mix was purchased from Applied Biosystems (Foster City, CA, USA). Primers were synthesized by Sigma-Aldrich. Detergent compatible protein assay kits (DC Protein Assay) were purchased from Bio-Rad Laboratories. Mouse anti-human ESR1 (Ab-15) MAB was from NeoMarkers, Inc. (Fremont, CA, USA). Rabbit anti-human VEGFA (sc-152-G) and goat antihuman actin (sc-1615) polyclonal antibodies were from Santa Cruz Biotechnology, Inc. (Santa Cruz, CA, USA). Mouse antihuman MMP9 (IM09L) and MMP2 (IM33) antibodies were purchased from Calbiochem (Gibbstown, NJ, USA). HRPconjugated anti-mouse and anti-goat secondary antibodies were purchased from Zymed (Carlsbad, CA, USA). Nitrocellulose membranes were obtained from Bio-Rad Laboratories. The Renaissance Western Blot Chemiluminescence Reagent Plus kits were acquired from Perkin Elmer Life Sciences (Waltham, MA, USA). X-Omatic films were purchased from American Imaging (South Plainfield, NJ, USA).

\section{Experimental design and tissue collection}

At birth, crossbred gilts (Sus scrofa domesticus) were assigned randomly to either nurse ad libitum $(N=10)$ or receive milk replacer by gavage $(50 \mathrm{ml} / 2 \mathrm{~h}$ for $48 \mathrm{~h} ; N=10)$, with or without exogenous RLX $(20 \mu \mathrm{g} / \mathrm{kg}$ BW, given i.m. in PBS every $6 \mathrm{~h}$ for $48 \mathrm{~h} ; \mathrm{N}=5$ ). The dose and timing of RLX administration were based on previous studies in neonatal gilts (Yan et al. 2008). Uteri were collected $3 \mathrm{~h}$ after the last treatment on PND 2. In addition, uteri were obtained from gilts prior to their consumption of milk at birth on PND O $(N=5)$. Neonatal gilts were killed for tissue collection using Beuthanasia-D Special while under surgical anesthesia. Care was taken to ensure that treatments were balanced for potential effects of litter $(N=13)$, and that sows were nursing litters of similar size.

Neonatal uterine tissues were removed, trimmed of fat and associated tissues, including the broad ligament, and wet weights were recorded. Tissues were then immersed in RNALater and stored at $-80^{\circ} \mathrm{C}$. Animals were obtained from the Auburn University Swine Research and Education Center, or from the Swine Unit of the New Jersey Agricultural Experiment Station, Rutgers University. All procedures involving animals were reviewed and approved by relevant Institutional Animal Care and Use Committees and were conducted in accordance with the Guide for the Care and 
Use of Agricultural Animals in Agricultural Research and Teaching (1999; Federation of Animal Science Society, Savoy, IL, USA).

\section{RNA isolation, CDNA generation, and real-time RT-PCR}

Total RNA was isolated from 30 to $50 \mathrm{mg}$ of whole uterine tissue cross-sections for each sample using TRI Reagent and the RNeasy Mini kit. Traces of DNA were removed using the RNase-Free DNase Set. RNA concentration and purity were evaluated by spectrophotometry. RNA integrity was checked by agarose gel electrophoresis and ethidium bromide staining to visualize sharp, clear $28 S$ and $18 S$ rRNA bands. RT was performed with 500 ng total RNA per sample using the PTC200 Peltier Thermal Cycler (Bio-Rad Laboratories) and SuperScript III First-Strand Synthesis System for RT-PCR. All procedures were carried out following the manufacturer's instructions.

Real-time quantitative RT-PCR (qPCR) was performed using an Applied Biosystems Gene Amp 7000 Sequence Detection System (Applied Biosystems) with the SYBR Green method following the universal thermal cycling parameters indicated by the manufacturer. Primers for qPCR were designed using Primer Express Software (Applied Biosystems) and synthesized by Sigma-Aldrich. All primer sequences were directed to the porcine genome (Table 1). To ensure specific amplification, controls including water only, no primers, and no template were included in the assay. The quality of the primers was evaluated by amplifying serial dilutions of the cDNA template. In addition, dissociation curves for each set of primers were checked to ensure no amplicon-independent amplification. PCR amplification products were analyzed by agarose gel electrophoresis to further confirm the absence of nonspecific amplification. Data were analyzed using the relative standard curve method for quantification of gene expression as described by Applied Biosystems (ABI User Bulletin 2, 2001). Standard curves were generated for each gene using twofold dilutions of cDNA generated from PND 2 uterine tissues obtained from gilts that were nursed (Larionov et al. 2005). Efficiencies for the reaction were calculated using the slope of the standard curves and ranged between 90 and $110 \%$ for each primer set. Target gene expression was normalized to the expression of porcine 18S. Data from qPCR analyses are presented as relative mRNA units. Data generated by qPCR for $18 S$ mRNA from each sample were analyzed to confirm the absence of treatment effects on this reference gene.

\section{Protein extraction and evaluation of ESR1, VEGFA, MMP2, and MMP9 expression}

Whole uterine tissue cross-sections (20-50 mg) were homogenized in $200 \mu \mathrm{l}$ lysis buffer (1\% Triton X-100, 10\% glycerol, $150 \mathrm{mM}$ Tris- $\mathrm{HCl}, 300 \mathrm{mM} \mathrm{NaCl}, 1 \mathrm{mM} \mathrm{MgCl}$, $\mathrm{pH}$ 7.5). Samples were then sonicated and centrifuged $\left(12000 \mathrm{~g}, 4{ }^{\circ} \mathrm{C}\right)$ for $30 \mathrm{~min}$, and the protein supernatant was removed and stored at $-20^{\circ} \mathrm{C}$. Protein concentration was measured using the DC Protein Assay kit (Bio-Rad Laboratories). To document target protein expression, uterine proteins $(30 \mu \mathrm{g})$ were resolved on $12.0 \%$ total monomer, Bis-Tris-HCl-buffered polyacrylamide gels under reducing conditions (non-reducing conditions for MMP9 to detect both the latent and the active forms, as suggested by the manufacturer) and transferred onto nitrocellulose membranes. After blocking in $10.0 \%$ non-fat dry milk in Tris-buffered saline containing Tween-20 (TBST; $25 \mathrm{mM}$ Tris ( $\mathrm{pH} 7.5$ ), $0.14 \mathrm{mM} \mathrm{NaCl}, 3 \mathrm{mM} \mathrm{KCl}$, and $0.05 \%$ Tween20), membranes were probed with either mouse anti-human ESR1 antibody (1:200), mouse anti-human MMP2 or MMP9 antibodies (1:2000), or rabbit anti-human VEGFA antibody (1:1000) overnight at $4{ }^{\circ} \mathrm{C}$. After washing with TBST, blots were incubated with either HRP-conjugated anti-mouse secondary antibody (1:1000) or anti-rabbit secondary antibody (1:1000) for $1 \mathrm{~h}$ at room temperature. Bound antibodies were detected by ECL. Protein loading was monitored using actin as a reference. In preliminary studies, antibody specificity was confirmed for ESR1 using ESR1-positive human MCF-7 mammary epithelial cells (positive control) and for VEGFA using PND 15 porcine small intestine. Antibodies against MMP2 and MMP9 were validated for immunoblotting as described previously (Ho et al. 2007). For all antibodies used, evidence of target protein detection was confirmed by a signal at the expected molecular size on the blot. Chemiluminescence signals were quantified by densitometry from film using Scion Image for Windows (Scion Corporation, Frederick, MD, USA). In circumstances where immunoblot signals were below background signals under identical exposure conditions, data were recorded as being nondetectable (ND).

\section{Statistical analysis}

Data were subjected to ANOVA using general linear model procedures available with SAS (SAS 2009-2010, Cary, NC, USA). For weights and uterine ESR1, VEGFA, MMP2, and MMP9 protein and mRNA levels, statistical models considered variation due to main effects of age, nursing, and RLX

Table 1 Porcine primer accession numbers and primer sequences for targeted uterine genes.

\begin{tabular}{llll}
\hline Gene & Accession no. & Forward primer & Reverse primer \\
\hline ESR1 & AF035775 & AGGGAGAGGAGTTTGTGTG & TCTCCAGCAGCAGGTCATAG \\
$V E G F A$ & AF318502 & AAGATCCGCAGACGTGTAAA & CACATCTGCAAGTACGTTCG \\
$M M P 9$ & DQ132879 & TGGATCCAAAACTACTCGGAAGAC & CGGACAAAGGCGTCG \\
$M M P 2$ & NM214192 & GAGCACCATCGAGACCATGA & TTGTAATTGGCACGTCGG \\
$R X F P 1$ & CA994862 & GCATCACTTTGAGGCAGAGACA & CCTCGGCAAAGACATTGCAT \\
$18 S$ & AF102857 & CCGCGGTTCTATTTTGTTGGTTT & CGGGCCGGGTGAGGTTTC \\
\hline
\end{tabular}


treatments. Preplanned contrasts were performed to determine the effects of neonatal age (PND 0 versus PND 2) and treatments for tissues obtained on PND 2, including i) nursing versus replacer; ii) nursing versus nursing $+\mathrm{RLX}$; and iii) replacer versus replacer $+R L X$. All error terms were identified based upon expectations of the mean squares for error. Data are expressed as least square S.E.M.

\section{Declaration of interest}

The authors declare that there is no conflict of interest that could be perceived as prejudicing the impartiality of the research reported.

\section{Funding}

This study was supported by the National Research Initiative Competitive Grant no. 2007-35203-18098 from the USDA National Institute of Food and Agriculture and NSF-EPS 0814103.

\section{Acknowledgements}

The authors thank Dr David Sherwood, University of Illinois, Urbana, IL, for providing the porcine RLX; Auburn University and Rutgers University undergraduate student research assistants (the 'pLacTeam'), Mr Alejandro Silva, and Animal Care Program staff for their assistance in these studies.

\section{References}

Almeida AA, Lopes CM, Silva AM \& Barrado E 2008 Trace elements in human milk: correlation with blood levels, inter-element correlations and changes in concentration during the first month of lactation. Journal of Trace Elements in Medicine and Biology 22 196-205. (doi:10. 1016/j.jtemb.2008.03.007)

Alvarez-Garcia I \& Miska EA 2005 MicroRNA functions in animal development and human disease. Development 132 4653-4662. (doi:10.1242/dev.02073)

Bagnell CA, Steinetz BG \& Bartol FF 2009 Milk-borne relaxin and the lactocrine hypothesis for maternal programming of neonatal tissues. Annals of the New York Academy of Sciences 1160 152-157. (doi:10. 1111/j.1749-6632.2009.03834.x)

Bartol FF, Wiley AA, Spencer TE, Vallet JL \& Christenson RK 1993 Early uterine development in pigs. Journal of Reproduction and Fertility. Supplement 48 99-116.

Bartol FF, Wiley AA \& Bagnell CA 2008 Epigenetic programming of porcine endometrial function and the lactocrine hypothesis. Reproduction in Domestic Animals 43 (Supplement 2) 273-279. (doi:10.1111/j.14390531.2008.01174.x)

Bartol FF, Wiley AA \& Bagnell CA 2009 Relaxin and maternal lactocrine programming of neonatal uterine development. Annals of the New York Academy of Sciences 1160 158-163. (doi:10.1111/j.1749-6632.2008. 03820.x)

Burrin DG, Davis TA, Ebner S, Schoknecht PA, Fiorotto ML, Reeds PJ \& McAvoy S 1995 Nutrient-independent and nutrient-dependent factors stimulate protein synthesis in colostrum-fed newborn pigs. Pediatric Research 37 593-599. (doi:10.1203/00006450-199505000-00006)

Cebe-Suarez S, Zehnder-Fjallman A \& Ballmer-Hofer K 2006 The role of VEGF receptors in angiogenesis; complex partnerships. Cellular and Molecular Life Sciences 63 601-615. (doi:10.1007/s00018-0055426-3)

Chapkin RS, Zhao C, Ivanov I, Davidson LA, Goldsby JS, Lupton JR, Mathai RA, Monaco MH, Rai D, Russell WM et al. 2010 Noninvasive stool-based detection of infant gastrointestinal development using gene expression profiles from exfoliated epithelial cells. American Journal of Physiology. Gastrointestinal and Liver Physiology 298 G582-G589. (doi:10.1152/ajpgi.00004.2010)

Chen JC, Wiley AA, Ho TY, Frankshun AL, Hord KM, Bartol FF \& Bagnell CA 2010 Transient estrogen exposure from birth affects uterine expression of developmental markers in neonatal gilts with lasting consequences in pregnant adults. Reproduction 139 623-630. (doi:10. 1530/REP-09-0454)

Crabbe T, loannou C \& Docherty AJ 1993 Human progelatinase A can be activated by autolysis at a rate that is concentration-dependent and enhanced by heparin bound to the C-terminal domain. European Journal of Biochemistry 218 431-438. (doi:10.1111/j.1432-1033.1993. tb18393.x)

Cullinan-Bove K \& Koos RD 1993 Vascular endothelial growth factor/ vascular permeability factor expression in the rat uterus: rapid stimulation by estrogen correlates with estrogen-induced increases in uterine capillary permeability and growth. Endocrinology 133 829-837. (doi:10.1210/en.133.2.829)

De Benedetti A \& Graff JR 2004 elF-4E expression and its role in malignancies and metastases. Oncogene 23 3189-3199. (doi:10.1038/ sj.onc. 1207545)

Donovan SM \& Odle J 1994 Growth factors in milk as mediators of infant development. Annual Review of Nutrition 14 147-167. (doi:10.1146/ annurev.nu.14.070194.001051)

Field CJ 2005 The immunological components of human milk and their effect on immune development in infants. Journal of Nutrition $1351-4$.

Frankshun AL, Ho TY, Steinetz BG, Bartol FF \& Bagnell CA 2009 Biological activity of relaxin in porcine milk. Annals of the New York Academy of Sciences 1160 164-168. (doi:10.1111/j.1749-6632.2008. 03822.x)

Graff JR, Boghaert ER, De Benedetti A, Tudor DL, Zimmer CC, Chan SK \& Zimmer SG 1995 Reduction of translation initiation factor 4E decreases the malignancy of ras-transformed cloned rat embryo fibroblasts. International Journal of Cancer 60 255-263. (doi:10.1002/ijc. 2910600221)

Grosvenor CE, Picciano MF \& Baumrucker CR 1993 Hormones and growth factors in milk. Endocrine Reviews 14 710-728. (doi:10.1210/ edrv-14-6-710)

Hartmann R, Meisel H, Hartmann R \& Meisel H 2007 Food-derived peptides with biological activity: from research to food applications. Current Opinion in Biotechnology 18 163-169. (doi:10.1016/j.copbio. 2007.01.013)

Hata T, Murakami K, Nakatani H, Yamamoto Y, Matsuda T \& Aoki N 2010 Isolation of bovine milk-derived microvesicles carrying mRNAs and microRNAs. Biochemical and Biophysical Research Communications 396 528-533. (doi:10.1016/j.bbrc.2010.04.135)

Ho TY, Yan W \& Bagnell CA 2007 Relaxin-induced matrix metalloproteinase-9 expression is associated with activation of the NF-kappaB pathway in human THP-1 cells. Journal of Leukocyte Biology $\mathbf{8 1}$ 1303-1310. (doi:10.1189/jlb.0906556)

Hu J, Zhang X, Nothnick WB \& Spencer TE 2004 Matrix metalloproteinases and their tissue inhibitors in the developing neonatal mouse uterus. Biology of Reproduction 71 1598-1604. (doi:10.1095/biolreprod.104. 031559)

Huang JC, Liu DY \& Dawood MY 1998 The expression of vascular endothelial growth factor isoforms in cultured human endometrial stromal cells and its regulation by 17 beta-oestradiol. Molecular Human Reproduction 4 603-607. (doi:10.1093/molehr/4.6.603)

Ing NH \& Ott TL 1999 Estradiol up-regulates estrogen receptor-alpha messenger ribonucleic acid in sheep endometrium by increasing its stability. Biology of Reproduction 60 134-139. (doi:10.1095/biolreprod60.1.134)

Iwahashi M, Muragaki Y, Ooshima A, Yamoto M \& Nakano R 1996 Alterations in distribution and composition of the extracellular matrix during decidualization of the human endometrium. Journal of Reproduction and Fertility 108 147-155. (doi:10.1530/jrf.0.1080147)

Kosaka N, Izumi H, Sekine K \& Ochiya T 2010 MicroRNA as a new immune-regulatory agent in breast milk. Silence 1 7. (doi:10.1186/1758907X-1-7) 
Kuo NT, Benhayon D, Przybylski RJ, Martin RJ \& LaManna JC 1999 Prolonged hypoxia increases vascular endothelial growth factor mRNA and protein in adult mouse brain. Journal of Applied Physiology $\mathbf{8 6}$ 260-264.

Langer P 2009 Differences in the composition of colostrum and milk in eutherians reflect differences in immunoglobulin transfer. Journal of Mammology 90 332-339. (doi:10.1644/08-MAMM-A-071.1)

Larionov A, Krause A \& Miller W 2005 A standard curve based method for relative real time PCR data processing. BMC Bioinformatics 662 . (doi:10.1186/1471-2105-6-62)

Lenhart JA, Ryan PL, Ohleth KM, Palmer SS \& Bagnell CA 2001 Relaxin increases secretion of matrix metalloproteinase- 2 and matrix metalloproteinase-9 during uterine and cervical growth and remodeling in the pig. Endocrinology 142 3941-3949. (doi:10.1210/en.142.9.3941)

Lonnerdal B 2003 Nutritional and physiologic significance of human milk proteins. American Journal of Clinical Nutrition 77 1537S-1543S.

Martelli M, Campana A \& Bischof P 1993 Secretion of matrix metalloproteinases by human endometrial cells in vitro. Journal of Reproduction and Fertility 98 67-76. (doi:10.1530/jrf.0.0980067)

Masters RA, Crean BD, Yan W, Moss AG, Ryan PL, Wiley AA, Bagnell CA \& Bartol FF 2007 Neonatal porcine endometrial development and epithelial proliferation affected by age and exposure to estrogen and relaxin. Domestic Animal Endocrinology 33 335-346. (doi:10.1016/ j.domaniend.2006.07.002)

Neufeld G, Cohen T, Gengrinovitch S \& Poltorak Z 1999 Vascular endothelial growth factor (VEGF) and its receptors. FASEB Journal 13 9-22.

Nishihara E, Nagayama Y, Inoue S, Hiroi H, Muramatsu M, Yamashita S \& Koji T 2000 Ontogenetic changes in the expression of estrogen receptor alpha and beta in rat pituitary gland detected by immunohistochemistry. Endocrinology 141 615-620. (doi:10.1210/en.141.2.615)

Nusser KD \& Frawley S 1997 Depriving neonatal rats of milk from early lactation has long-term consequences on mammotrope development. Endocrine 7 319-323. (doi:10.1007/BF02801325)

O'Connell JP, Willenbrock F, Docherty AJ, Eaton D \& Murphy G 1994 Analysis of the role of the $\mathrm{COOH}$-terminal domain in the activation, proteolytic activity, and tissue inhibitor of metalloproteinase interactions of gelatinase B. Journal of Biological Chemistry 269 14967-14973.

O'Farrell TJ \& Pourmotabbed T 2000 Identification of structural elements important for matrix metalloproteinase type $\mathrm{V}$ collagenolytic activity as revealed by chimeric enzymes. Role of fibronectin-like domain and active site of gelatinase B. Journal of Biological Chemistry 275 27964-27972. (doi:10.1074/jbc.M003936200)

Ogra SS, Weintraub D \& Ogra PL 1977 Immunologic aspects of human colostrum and milk. III. Fate and absorption of cellular and soluble components in the gastrointestinal tract of the newborn. Journal of Immunology 119 245-248.

Osterlundh I, Holst H \& Magnusson U 1998 Hormonal and immunological changes in blood and mammary secretion in the sow at parturition. Theriogenology 50 465-477. (doi:10.1016/S0093-691X(98)00153-8)

Parry LJ, McGuane JT, Gehring HM, Kostic IG \& Siebel AL 2005 Mechanisms of relaxin action in the reproductive tract: studies in the relaxin-deficient (Rlx - /-) mouse. Annals of the New York Academy of Sciences 1041 91-103. (doi:10.1196/annals.1282.013)

Pavitt GD 2005 elF2B, a mediator of general and gene-specific translational control. Biochemical Society Transactions 33 1487-1492. (doi:10.1042/ BST20051487)

Playford RJ, Macdonald CE \& Johnson WS 2000 Colostrum and milkderived peptide growth factors for the treatment of gastrointestinal disorders. American Journal of Clinical Nutrition 72 5-14.

Salmon H, Berri M, Gerdts V \& Meurens F 2009 Humoral and cellular factors of maternal immunity in swine. Developmental and Comparative Immunology 33 384-393. (doi:10.1016/j.dci.2008.07.007)

Sherwood OD 2004 Relaxin's physiological roles and other diverse actions. Endocrine Reviews 25 205-234. (doi:10.1210/er.2003-0013)
Sherwood CD \& O'Byrne EM 1974 Purification and characterization of porcine relaxin. Archives of Biochemistry and Biophysics 160 185-196. (doi:10.1016/S0003-9861(74)80025-1)

Shulman RJ 1990 Oral insulin increases small intestinal mass and disaccharidase activity in the newborn miniature pig. Pediatric Research 28 171-175.

Simmen FA, Cera KR \& Mahan DC 1990 Stimulation by colostrum or mature milk of gastrointestinal tissue development in newborn pigs. Journal of Animal Science 68 3596-3603.

Sonenberg N \& Hinnebusch AG 2009 Regulation of translation initiation in eukaryotes: mechanisms and biological targets. Cell 136 731-745. (doi:10.1016/j.cell.2009.01.042)

Tarleton BJ, Wiley AA \& Bartol FF 1999 Endometrial development and adenogenesis in the neonatal pig: effects of estradiol valerate and the antiestrogen ICl 182,780. Biology of Reproduction 61 253-263. (doi:10. 1095/biolreprod61.1.253)

Tarleton BJ, Braden TD, Wiley AA \& Bartol FF 2003 Estrogen-induced disruption of neonatal porcine uterine development alters adult uterine function. Biology of Reproduction 68 1387-1393. (doi:10.1095/ biolreprod.102.011346)

Unemori EN, Erikson ME, Rocco SE, Sutherland KM, Parsell DA, Mak J \& Grove BH 1999 Relaxin stimulates expression of vascular endothelial growth factor in normal human endometrial cells in vitro and is associated with menometrorrhagia in women. Human Reproduction $\mathbf{1 4}$ 800-806. (doi:10.1093/humrep/14.3.800)

Welter H, Wollenhaupt K, Tiemann U \& Einspanier R 2003 Regulation of the VEGF-system in the endometrium during steroid-replacement and early pregnancy of pigs. Experimental and Clinical Endocrinology \& Diabetes 111 33-40. (doi:10.1055/s-2003-37498)

Yan W, Ryan PL, Bartol FF \& Bagnell CA 2006a Uterotrophic effects of relaxin related to age and estrogen receptor activation in neonatal pigs. Reproduction 131 943-950. (doi:10.1530/rep.1.00762)

Yan W, Wiley AA, Bathgate RA, Frankshun AL, Lasano S, Crean BD, Steinetz BG, Bagnell CA \& Bartol FF $2006 b$ Expression of LGR7 and LGR8 by neonatal porcine uterine tissues and transmission of milk-borne relaxin into the neonatal circulation by suckling. Endocrinology $\mathbf{1 4 7}$ 4303-4310. (doi:10.1210/en.2006-0397)

Yan W, Chen J, Wiley AA, Crean-Harris BD, Bartol FF \& Bagnell CA 2008 Relaxin (RLX) and estrogen affect estrogen receptor alpha, vascular endothelial growth factor, and RLX receptor expression in the neonatal porcine uterus and cervix. Reproduction 135 705-712. (doi:10.1530/ REP-08-0014)

Zabielski R, Godlewski MM \& Guilloteau P 2008 Control of development of gastrointestinal system in neonates. Journal of Physiology and Pharmacology 59 (Supplement 1) 35-54.

Zeng ZS, Cohen AM \& Guillem JG 1999 Loss of basement membrane type IV collagen is associated with increased expression of metalloproteinases 2 and 9 (MMP-2 and MMP-9) during human colorectal tumorigenesis. Carcinogenesis 20 749-755. (doi:10.1093/carcin/20.5.749)

Zhang X, Christenson LK \& Nothnick WB 2007 Regulation of MMP-9 expression and activity in the mouse uterus by estrogen. Molecular Reproduction and Development 74 321-331. (doi:10.1002/mrd.20582)

Zhou S, Wang GP, Liu C \& Zhou M 2006 Eukaryotic initiation factor 4E (elF4E) and angiogenesis: prognostic markers for breast cancer. BMC Cancer 6 231. (doi:10.1186/1471-2407-6-231)

Received 28 July 2010

First decision 24 September 2010

Revised manuscript received 4 February 2011

Accepted 11 February 2011 